\title{
Discharge Policy Analysis in Prince Hamzah Hospital
}

\author{
Hamzah M. Alghzawi1,2, Rudaina A. Hourani1, Baraa M. Alrashaida², \\ Ayman Hamdan-Mansour' ${ }^{1}$, Magda Bayomi ${ }^{1}$ \\ ${ }^{1}$ Department of Community Health Nursing, Al Farabi College, Riyadh, KSA \\ ${ }^{2}$ Medical Department, Prince Hamzah Hospital, Amman, Jordan \\ Email: HamzahJordan87@gmail.com, Rn.hamzah@yahoo.com
}

Received 17 October 2014; revised 30 November 2014; accepted 15 December 2014

Copyright (C 2014 by authors and Scientific Research Publishing Inc.

This work is licensed under the Creative Commons Attribution International License (CC BY). http://creativecommons.org/licenses/by/4.0/

(c) (i) Open Access

\begin{abstract}
A discharge policy is intended to ensure provision of fit, timely discharge arrangements to an appropriate safe environment for all patients on completion of their hospital care. This paper analyzes the current discharge policy in Prince Hamzah Hospital, to discover if it can be made more effective. The analysis is based on Patton and Sawicki's six-step model of policy analysis. According to Patton and Sawicki's six-step model of policy analysis, the process involves problem identification, determining policy objectives, establishing evaluation criteria, suggesting and assessing possible alternatives, and implementing, monitoring, and evaluating the policy after modification. It was concluded that the policy should remain a live document that could be refined, updated and expanded as appropriate.
\end{abstract}

\section{Keywords}

Discharge, Policy, Analysis, Patient

\section{Introduction}

Provision of high-quality care at the right time, in the right place and delivered by the right persons is of vital importance in reducing pressure on hospital services. Fast and well-organized discharge of patients from acute settings to the next level of care playing a vital part in ensuring capacity is available for patients needing to access acute care beds. Equally important is the necessary to guarantee that the patients' transition from acute care settings to community care is safe, well coordinated, and well communicated [1].

Discharge planning begins at the patient's early assessment or within the first day of admission or initiation of a care [1]. It needs the development and application of a recognized discharge plan, which takes into account 
any previous assessment or care plans.

The main goal of the discharge planning is to ensure permanence of care, so the plan is reviewed and modified to take into account changes in individual housing and social situations, and it should be tailored to the patient's characteristics [2]. The development of discharge planning is the duty of all the healthcare providers involved with the patient. It is, however, revised by a named person who has accountability for ensuring that all aspects of planning have been addressed by the day of discharge from the care setting.

The discharge policy should be developed to support good practice by providing direction for staff involved in the discharge planning process. The aim of the policy should be to ensure provision of appropriate, timely discharge arrangements to an appropriate safe environment for all patients on completion of their care [3].

Prince Hamzah Hospital is a public hospital located in Jordan, in the capital of Amman, featuring a total built-up area of 60,000 sqm and comprising 10 floors with 500-bed capacity, with the option of future expansion [4].

This paper aims to analyze the discharge policy in Prince Hamzah Hospital based on a model of policy analysis, and then suggests alternatives and principles in order to refine, modify, update and expand the current discharge policy to be more efficient and capable on overcoming its defects.

\section{Method}

In this paper, the analysis of current discharge policy follows Patton and Sawicki six-step model [5] as shown in Figure 1. The steps are: problem identification, determining policy objectives, establishing evaluation criteria, suggesting possible alternatives, assessing these possible alternatives, and implementing, monitoring and evaluating the new, modified policy.

\section{Results}

\subsection{Problem Identification}

The current discharge policy states that the decision to and timing of discharge is the responsibility of the attending physician and is based on the physician's assessment of the patient's medical condition.

The problems associated with this discharge process are that some patients are readmitted to the hospital within a short period of time, which means unplanned readmission, and some patients having delays in the discharge process for reasons not related to their medical condition, resulting in an increased length of stay; also, some patients are discharged from the hospital without satisfaction about their medical care and health improvement.

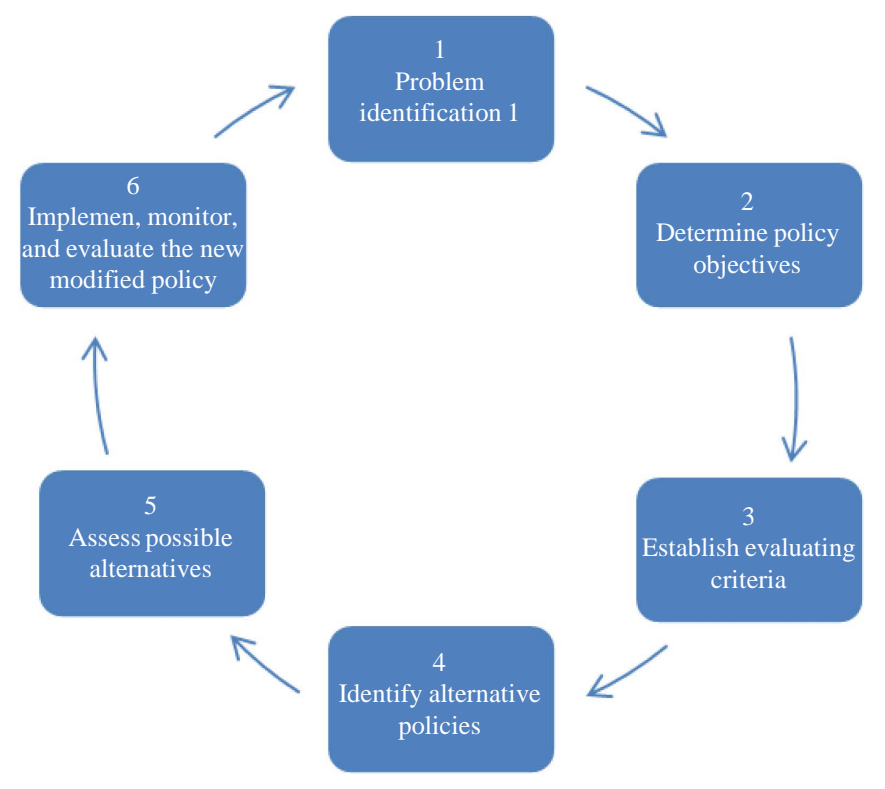

Figure 1. Patton and Sawicki six-step model. 
These negative outcomes result from weak points in the policy, which can be summarized as follows:

- The decision to discharge is based on the opinion of the physician who is responsible for the patient, and is not based on the opinion of a multi-disciplinary team.

- The decision for discharge is based only on the physician's assessment of the patient's medical needs, not on the patient's comprehensive needs.

- The policy does not state the consultant's responsibility in determining the estimated discharge date after initial assessment by medical staff.

- The policy does not clearly state the responsibilities of all clinical staff, such as nursing, medical and pharmacy staff.

As is clear, the current discharge policy is incomplete in its content and does not cover all conditions; its current application has negative outcomes which affect cost, effectiveness, equity, and other issues. Given these undesirable negative outcomes, it is important to establish new strategies to resolve them. The question of how to avoid the negative outcomes of applying any discharge policy will be discussed in this paper.

When we review the discharge policies in institutions like the King Hussein Cancer Centre and the University Hospitals of Leicester, we find that these institutions counter the negative outcomes by adding some modifications to their policies. Therefore, following the experience of these institutions, we will suggest possible alternatives and recommendations to modify the current discharge policy, in order to improve its discharge planning process.

\subsection{Objectives of Discharge Policy}

Certain objectives and outcomes should be considered when developing a discharge policy, including:

- Best practice in discharge planning for patients' safe transfer from the health setting to the next level of care.

- Advance principles of communication within the multi-disciplinary team of health care providers.

- Staff in clinical areas have access to and awareness of up-to-date relevant national and local policies and guidelines to enable highest standards of practice in discharge planning.

- Discharge planning begins prior to, or immediately on, admission to hospital and continues throughout the patient's acute hospital admission.

- The multi-disciplinary nature of discharge planning is maintained and involves all appropriate health and social care professionals throughout the pathway of care.

- The patient is involved and has the opportunity to influence and receive appropriate information throughout the discharge planning process.

All of these objectives, if achieved, will result in desirable outcomes that can be observed and measured, and are reflected in reduced length of stay, fewer unplanned admissions, improved patient satisfaction, cost effectiveness in all health care settings, improved health outcomes, and ensuring stability of care [6].

\subsection{Evaluation Criteria for Discharge Policy}

Good policy will clearly identify the issues that it deals with it. Also, good policy should focus on problem solving of the existing defects. This involves precise analysis of available statistics, review role models from practice elsewhere, recognize patients need, and involve experts at clinical areas in policy making.

Research evidence [1] indicates that effective discharge planning should include:

- Patient focus.

- Clear communication ways between individuals.

- A focus on quality, safety and risk management.

- Providing effective care.

- Clear role description for health care providers.

- Continuity of health care.

- A focus on tailoring discharge planning to outfit individual needs.

Furthermore, good policy must have actions, and actions must be designed to achieve positive outcomes such as reduce length of stay, avoid unnecessary readmission, cost effectiveness, high quality care, continuity of care after discharge, and patients satisfaction. All of these outcomes should be used as criteria to evaluate the effectiveness of discharge process. 


\subsection{Possible Alternatives for Discharge Policy}

The following considerations could be added to the current discharge policy:

Perform comprehensive patient assessment within twenty-four hours of admission as a basis for the discharge process. This comprehensive assessment includes, in addition to medical status: social circumstances and existing social support, known lifestyle, family support in relation to the patient's physical and mental capabilities, patient and family education needs, and unmet needs [7].

Patients will not be discharged until the consultants, along with the multi-professional team where applicable, have agreed and are satisfied that the patient is medically stable and that appropriate care has been planned and arranged [7].

All patients admitted electively will be made aware of their expected discharge date upon admission. Elective patients are also advised that they may be asked to vacate their bed on the morning of discharge and should therefore arrange to be collected prior to 12 noon. Also, they should be aware of the initial medical addressed needs, to give medical justification for every day beyond that of expected discharge [7].

Medical and nursing staff will keep the patient and family informed of the patient's progress and plans towards discharge. Written notes of key discussions and decisions will be recorded in the medical notes in order to promote multi-disciplinary communication [7].

The professional responsibility of clinical staff in the discharge process should be clearly determined, to make the process more effective and to overcome any defects in the process. A summary of staff responsibilities follows [7] [8].

\subsubsection{Nursing Staff}

1) It is the responsibility of the ward manager to maintain a strategic overview of the discharge process and all professionals' input into it.

2) It is the responsibility of the discharge nurse to communicate the overall plan for the patient, his or her family and the related healthcare team. The discharge nurse will also ensure that appropriate referrals are made, checking their arrangements, including the provision of essential equipment and services that should be in place when the patient is ready for discharge.

3) The discharge nurse should keep the patient and/or family fully informed, provide relevant health education, and liaise with required nursing services; for specialist requirements this liaison should take place at least 48 hours in advance of discharge.

4) The discharge nurse should:

a) Ensure (where applicable) that:

- Pre-discharge assessments are carried out.

- The discharge order is written by physician to start discharge process.

- A discharge summary is completed and a copy is retained in the patient's notes.

- Appropriate written and/or verbal advice is given to the patient/family prior to discharge.

- Pre-discharge home visits are carried out and any follow-up visits post-discharge are arranged (for hospice patients).

- Essential aids and necessary medical supplies are provided, e.g. stocking aids, feeding equipment.

b) Provide discharge information to the patient and family when appropriate or to other specialist services, e.g. dietitian, speech therapist, physiotherapy, within five days of discharge.

c) Organize suitable transport arrangements, e.g. ambulance/private transport.

d) Ensure that medication, dressings, dietary arrangements and other aspects of self-care have been organized and are fully explained to the patient verbally and/or in writing four hours in advance of discharge or one working day if the patient has complex needs.

\subsubsection{Medical Staff}

It is the responsibility of the medical staff to coordinate medical input and treatment plans, and decide, in consultation with other disciplines, the date of discharge. They must also:

- Complete referrals to professions allied to medicine as appropriate for those particular categories of patient for whom a medical referral is required.

- Write a discharge order and complete discharge summary with detailing diagnosis, medication and any other 
relevant medical information. The discharge prescription should be prepared at least four hours in advance of the planned discharge time or one working day in the case of patients with complex needs. Where a patient is particularly vulnerable, telephone required services prior to discharge.

- Prepare a full formal discharge summary within seven days of the patient's discharge.

- Specify any review requirements they may have.

\subsubsection{Pharmacy Staff}

The Pharmacist will ensure that a three-day supply of prescribed medication is dispensed for immediate needs. Information and counselling on the administration of medicines will be provided to appropriate patient/family and documented in the patient's notes.

\subsection{Assessment of Possible Alternatives}

Many possible alternatives and principles could be added to the available discharge policy; these alternatives are summarized in Table 1. First is not to discharge the patient until the consultants, along with the multi-professional team, where applicable, have agreed that the patient is medically stable and that appropriate care has been planned and arranged. In this alternative policy, discharge planning should begin as soon as possible after admission. It could be concluded that application of this alternative policy will be more efficient because the decision of the multi-professional team is more precise, safe, and more appropriate than the decision of a single person. In addition, it will be effective in decreasing unplanned admissions within a short time of discharge.

The second alternative is to perform a comprehensive patient assessment within twenty-four hours of admission, and to use this in the discharge process. This comprehensive assessment includes, in addition to medical status: social circumstances and existing social support, known lifestyle, family support in relation to the patient's physical and mental capabilities, and patient and family education needs. These notes should be accessible, at ward level, to the multi-disciplinary team. Based on the gathered information, appropriate referrals to other disciplines will be made within 24 hours of completion of the initial assessment. In this policy, the initial

Table 1. Display and distinguish among alternatives.

\begin{tabular}{|c|c|c|c|c|}
\hline Alternatives & Advantages (Strengths) & $\begin{array}{l}\text { Disadvantages } \\
\text { (Weakness) }\end{array}$ & Best Case Scenario & Worst Case Scenario \\
\hline $\begin{array}{l}\text { Discharge by the } \\
\text { multi-disciplinary } \\
\text { team }\end{array}$ & Safe, and appropriate discharge & $\begin{array}{l}\text { Time-consumed, } \\
\text { require effective } \\
\text { communication }\end{array}$ & $\begin{array}{l}\text { "When there is effective } \\
\text { coordination between } \\
\text { members of } \\
\text { multidisciplinary team" }\end{array}$ & $\begin{array}{l}\text { "In the absent of } \\
\text { coordination of } \\
\text { multidisciplinary team } \\
\text { members" }\end{array}$ \\
\hline $\begin{array}{l}\text { Perform } \\
\text { comprehensive } \\
\text { patient assessment } \\
\text { within twenty-four } \\
\text { hours of admission }\end{array}$ & $\begin{array}{l}\text { Appropriate referrals to other } \\
\text { disciplines. Identify on patients } \\
\text { with special needs } \\
\text { Overcome any non medical } \\
\text { factor could delay discharge }\end{array}$ & $\begin{array}{l}\text { Comprehensive } \\
\text { assessment requires } \\
\text { highly skill and } \\
\text { cooperation of } \\
\text { multidiscipline }\end{array}$ & $\begin{array}{l}\text { "When the assessment } \\
\text { performed by skillful } \\
\text { persons” }\end{array}$ & $\begin{array}{l}\text { "In the absent of skill } \\
\text { to perform the } \\
\text { assessment" }\end{array}$ \\
\hline $\begin{array}{l}\text { Determine } \\
\text { estimated discharge } \\
\text { date (EDD) }\end{array}$ & $\begin{array}{l}\text { Enhance achievement of care } \\
\text { plane objectives with specific } \\
\text { time frame } \\
\text { Give indicator about available } \\
\text { bed over the time }\end{array}$ & $\begin{array}{l}\text { To determine EDD } \\
\text { within } 24 \text { hour based } \\
\text { on initial assessment } \\
\text { is difficult }\end{array}$ & $\begin{array}{l}\text { "When the determination } \\
\text { is based on proper } \\
\text { comprehensive } \\
\text { assessment" }\end{array}$ & $\begin{array}{l}\text { "When the } \\
\text { determination is based } \\
\text { on improper, non } \\
\text { comprehensive } \\
\text { assessment" }\end{array}$ \\
\hline $\begin{array}{l}\text { Involved patients } \\
\text { and their families } \\
\text { in the discharge } \\
\text { planning }\end{array}$ & $\begin{array}{l}\text { Enable them to understand and } \\
\text { contribute to their discharge } \\
\text { plan and make decisions for } \\
\text { their future care } \\
\text { Improve their satisfaction }\end{array}$ & $\begin{array}{l}\text { It require cooperative } \\
\text { patients and families }\end{array}$ & $\begin{array}{l}\text { "When patients and their } \\
\text { families are cooperative" }\end{array}$ & $\begin{array}{l}\text { "In the absent of } \\
\text { cooperation" }\end{array}$ \\
\hline $\begin{array}{l}\text { Determine the } \\
\text { responsibility of } \\
\text { each health care } \\
\text { team member in } \\
\text { discharge planning }\end{array}$ & $\begin{array}{l}\text { Ensure that the high standards } \\
\text { of discharge planning are } \\
\text { maintained and applied } \\
\text { It makes it easy to determine } \\
\text { the cause of defect in discharge } \\
\text { process }\end{array}$ & $\begin{array}{l}\text { It requires high level } \\
\text { of coordination }\end{array}$ & $\begin{array}{l}\text { "In the exist of effective } \\
\text { process to control } \\
\text { adherence to the } \\
\text { responsibilities" }\end{array}$ & $\begin{array}{l}\text { "In the absent of } \\
\text { effective process to } \\
\text { control responsibilities } \\
\text { adherence" }\end{array}$ \\
\hline
\end{tabular}


assessment will focus on different individual needs such as psychosocial needs, dietary needs, and palliative services. Ongoing assessment will be performed and includes revision of information gathered at the initial assessment; this is particularly important when it has not been possible to gather all the necessary information within the first 24 hours.

The third alternative is to make it the responsibility of the consultant to ensure that all patients in his/her care have an estimated discharge date (EDD) within 24 hours of admission to hospital, and to review this daily. By applying this alternative, the healthcare providers will be better able to achieve the expected goals within the expected timeframe. Also, it will provide indicators about the availability of beds over time. In addition, the estimated discharge date will be discussed and agreed with patients and their relatives, and any changes to this date will be discussed with all stakeholders.

The fourth alternative is to involve patients and relatives in the discharge planning wherever possible, and to make them know expected discharge date, and outpatient medications.

The fifth alternative is to clearly determine the responsibility of each member of the healthcare team. This will ensure that the high standards of discharge planning are maintained and applied, and make it easy to determine the cause of any defect in the discharge process. Furthermore, all of the supposed responsibilities should be applicable for each member in the healthcare team, in order to promote the adherence to these responsibilities and make the discharge process more effective.

The sixth alternative is to develop a comprehensive discharge plan checklist to be checked before 24 hrs of leaving hospital. This checklist is necessary to insure that all patients' needs are considered.

The seventh alternative is that every patient in hospital should be reviewed prior to discharge day, in order to determine what level of aftercare will be necessary to enable him or her to live safely without complains.

The eighth alternative is patient education. Each patient, prior discharge, should be educated about healthy lifestyles, medication, primary health care centers and follow up care. Also, all of that information should be given to the discharged patient as a written material to be revised at any time.

\subsection{Implementing, Monitoring, and Evaluating the Policy}

To implement the modified discharge policy, the following essential elements should be covered in practice guidelines [7]:

- "A goal, which reflects a shared vision for discharge planning".

- "Definitions, to make certain a shared understanding of terms used in discharge planning".

- "A flow chart for discharge planning, for both simple and complex admissions, to define a process or pathway to regulate discharge practices".

- "Discharge planning documentation, to streamline the documentation which supports best practice discharge planning, including discharge forms, checklist, a risk assessment tool and an evaluation tool”.

- "Staff education and training, to ensure staff have the necessary skills, knowledge and attitudes to provide best practice discharge planning".

- "Patient information, to engage, inform, and assist staff involved in the discharge planning process both prior to and after discharge".

- "Best practice or standards for discharge planning, to ensure that all discharge planning is to an acceptable standard”.

- "Performance indicators, to enable quality improvement and benchmarking".

Furthermore, to monitor and evaluate the performance of the discharge policy, the following major standards should be considered in the monitoring and evaluating process [1]:

- Regular review of unprofessional and multi-professional standards relating to the discharge of patients from the hospital. These standards should cover different aspects of the discharge process and be agreed upon with all relevant professionals. Standards should be well defined, easily measurable and regularly audited.

- The members of multi-professional team must recognize their role description in discharge planning, and be developed by training programs.

- Regular monitoring of the numbers of patients who have exceeded their expected length of stay (where this is predictable) and agreement on targets for particular clinical categories as appropriate.

- Regularly review of the number of patients clinically fit for discharge but whose discharge is delayed for non-clinical reasons (e.g. social problems, lack of aids); and to review liaison arrangements with other pro- 
fessionals, e.g. care managers, and their role in delayed discharges.

- Undertaking at least annual surveys looking at the quality of discharge and patient satisfaction levels.

- Consider a system of "discharge tracking" which would allow a random sample of patients to be closely followed after discharge. This would show whether agreed arrangements were followed at home and whether these arrangements were satisfactory.

- Regular review of all major complaints relating to patient discharge, and ensuring that appropriate corrective action has been taken and documented.

- Ensure that examples of good practice relating to the discharge process are widely disseminated to relevant departments within the hospital; and encourage collaborative audit where relevant and practical.

\section{Discussion}

Discharge planning begins with a patient's initial assessment or within the first day of admission. Discharge policy should aim to ensure provision of fit, timely discharge arrangements to an appropriate safe environment for all patients on completion of their care. Discharge policy from any health care institution should be developed in a way that supports good practice by providing direction for healthcare providers involved in the discharge planning process.

There are some negative aspects in patient discharge process at Prince Hamzah Hospital. These negative aspects are represented by unplanned readmission, delay in the discharge process and increasing length of stay, unavailability of beds, and lack of patient satisfaction. Also, these negative aspects affect on cost, effectiveness, equity, and other issues. Therefore, it was necessary to make an analysis for discharge policy at Prince Hamzah Hospital in order to overcome those negative aspects and improve the discharge process in general.

This paper analyzed discharge policy at Prince Hamzah Hospital based on the six-step model of policy analysis by Patton and Sawicki [5]. The first step, problem identification, involved stating the problem meaningfully, determining the magnitude and extent of the problem, and continually redefining the problem in light of what is possible. The second step, setting objectives for the discharge policy, involved considering the objectives and outcomes to be achieved. The third step involved setting evaluation criteria for discharge policy and determining criteria for good policy. The last three steps of six-step model of policy analysis involved suggesting alternatives, assessing each of these possible alternatives, and describing the process of implementing, monitoring, and evaluating the policy.

After the analysis was done, successful discharge policy has been reviewed at other health institutions like King Hussein Cancer Centre and the University Hospitals of Leicester. Some principle is highly recommended to be added to discharge policy at Prince Hamzah Hospital such as such as performing comprehensive patient assessment within twenty-four hours, basing the discharge process on consultation with the multi-disciplinary team, involving the patient and their family in the discharge process, and determining the responsibility of each member of the healthcare team.

\section{Conclusion}

Overall, it could be concluded that discharge policy at Prince Hamzah Hospital should keep a live document which could be refined, modified, updated and expanded as required.

\section{References}

[1] ACT Health (2006) Discharge Planning Policy. http://www.act.gov.au/health

[2] Wibe, T., Ekstedt, M. and Helles, R. (2014) Information Practices of Health Care Professionals Related to Patient Discharge from Hospital. Informatics for Health and Social Care, 39.

[3] Silow-Caroll, S.E., Edwards, J.N. and Lashbrook, A. (2011) Reducing Hospital Readmissions: Lessons from TopPerforming Hospitals. http://www.commonwealthfund.org/

[4] Mostaqbal’s Legacy (2013) http://www.acepo.jo/projects/buildings/healthcare

[5] Patton, C. and Sawicki, D. (1993) Basic Methods of Policy Analysis and Planning. Prentice-Hall, Upper Saddle River.

[6] Shepperd, S., McClaran, J., Phillips, C.O., Lannin, N.A., Clemson, L.M., McCluskey, A., Cameron, I.D. and Barras, S.L. (2010) Discharge Planning from Hospital to Home. Cochrane Database of Systematic Reviews, 1, CD000313.

[7] University Hospital of Leicester (2011) Discharge Policy for Adult Patient Leaving Hospital. 
https://www.whatdotheyknow.com

[8] Maramba, P.J., Richards, S., Myers, A.L. and Larrabee, J.H. (2014) Discharge Planning Process: Applying a Model for Evidence-Based Practice. Journal of Nursing Care Quality, 19, 123-129.

http://dx.doi.org/10.1097/00001786-200404000-00009 
Scientific Research Publishing (SCIRP) is one of the largest Open Access journal publishers. It is currently publishing more than 200 open access, online, peer-reviewed journals covering a wide range of academic disciplines. SCIRP serves the worldwide academic communities and contributes to the progress and application of science with its publication.

Other selected journals from SCIRP are listed as below. Submit your manuscript to us via either submit@scirp.org or Online Submission Portal.
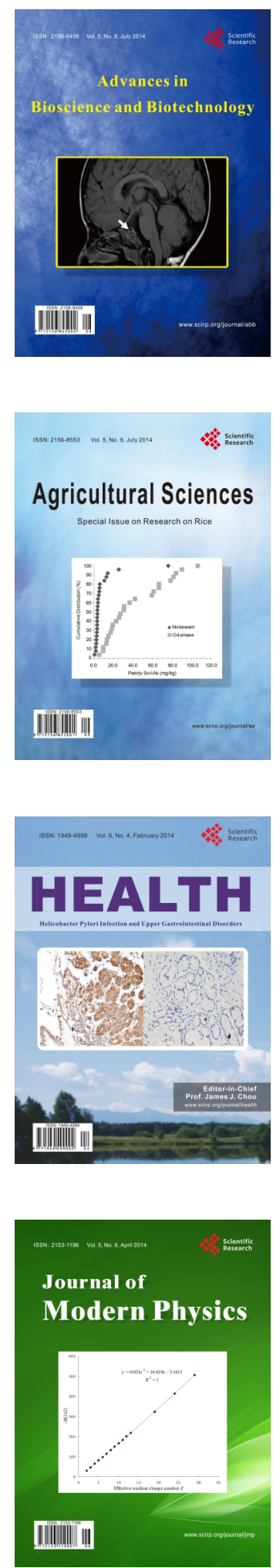
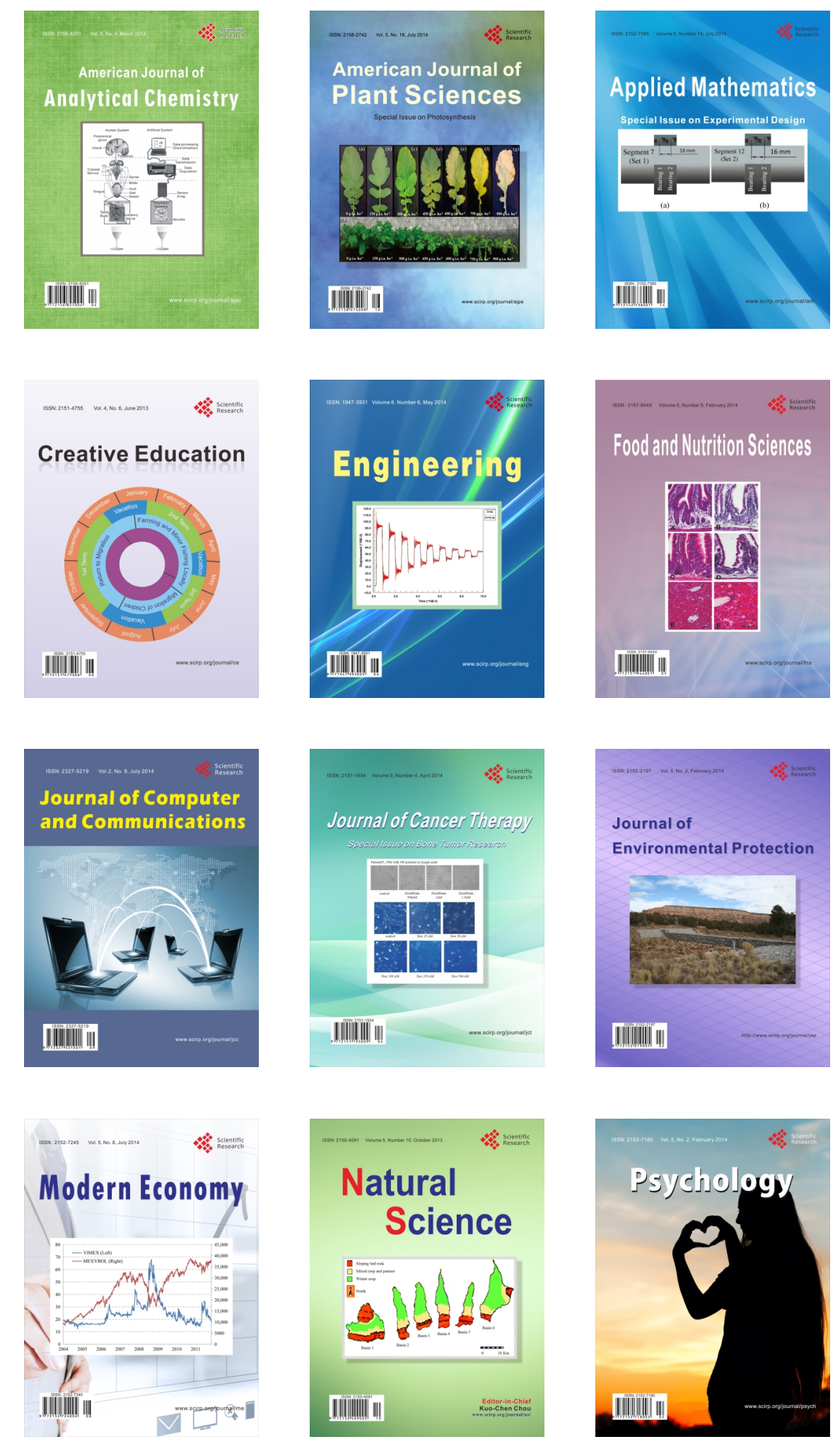